\title{
Análise Microestrutural e Tenacidade ao Impacto da ZAC do Aço inoxidável Ferrítico com 11\% Cr
}

\section{(Microstructural Analysis and Impact Toughness of HAZ of Ferritic Stainless Steel with $11 \% \mathrm{Cr}$ )}

\author{
Temistocles de Sousa Luz ${ }^{1}$, Jesualdo Pereira Farias ${ }^{2}$, Valtair Antonio Ferraresi ${ }^{3}$ \\ ${ }^{1}$ Universidade Federal do Espírito Santo, Centro Tecnológico, Departamento de Engenharia Mecânica, Vitória, Espírito Santo, \\ Brasil, temistocles.luz@ct.ufes.br \\ ${ }^{2}$ Universidade Federal do Ceará, Fortaleza, Centro de Tecnologia, Departamento de Engenharia Metalúrgica e de Materiais, Ceará, \\ Brasil. \\ ${ }^{3}$ Universidade Federal de Uberlândia, Faculdade de Engenharia Mecânica, Faculdade de Engenharia Mecânica, Uberlândia, Minas \\ Gerais, Brasil.
}

\section{Resumo}

O aço inoxidável ferrítico possibilita, em função de suas características, o uso em diversos campos da engenharia. Dentre esses é possivel citar a industria do petróleo e gás, de celulose açucareira, de transporte, entre outras. Atualmente, o desenvolvimento de novas ligas para a substituição dos aços ao carbono no que se refere ao setor de transporte de carga, levou muitos fabricantes a adotarem a liga ferrítica com base de cromo entre $11 \%$ e 12\%, implementando a tal situação, uma maior vida util. A utilização dessa nova classe de aço inoxidável ferrítico gera uma demanda no que tange à pesquisas das soldas desses aços. Neste trabalho, buscou-se analisar a região soldada de um aço inoxidável ferrítico experimental contendo 11\% de cromo, realizando para tal um estudo de sua microestrutura, e tenacidade ao impacto do metal de base e da zona afetada pelo calor (ZAC). A avaliação mostrou bons resultados nas propriedades mecânicas medidas nas duas regiões analisadas. Entretanto, verificou-se uma perda acentuada da tenacidade ao impacto na ZAC em relação ao metal de base.

Palavras-chave: aço inoxidável ferrítico, tenacidade ao impacto, zona afetada pelo calor, microestrutura.

\begin{abstract}
Ferritic stainless steel is used in various sectors of engineering, such as in oil and gas industry, cellulose, or transport. New alloys are currently been developed to replace carbon steel in cargo transportation sector, which has led the industry to use ferritic alloys with chromium contents near 12\%, increasing the mechanical and chemical properties. The use of this new class of ferritic stainless steel creates a demand concerning research in welding these steels. In this study, it is analyzed the microstructure and impact toughness of the parent metal and heat affected zone (HAZ) in a ferritic stainless steel containing $11 \%$ Cr. Good mechanical properties were observed in both regions, though there was a marked loss in the impact toughness of the HAZ compared to the base metal.
\end{abstract}

Key-words: ferritic stainless steel, impact toughness, HAZ, microstructural

\section{Introdução}

Comparado aos aços ao carbono, as ligas contendo teores de cromo em torno de $12 \%$ têm uma boa resistência à corrosão. Embora tenham custos iniciais mais altos, a vida útil das ligas contendo esses teores de cromo tende a ser bem maior, levando dessa forma a baixos custos de manutenção, mostrando dessa forma vantagens significativas em termos econômicos e ambientais. O aço de classe UNS S41003 é a primeira classe de aços inoxidáveis ferríticos com baixos teores de carbono que detém as características mecânicas dos aços ao carbono e dos aços inoxidáveis $[1,2]$. Recentemente tais materiais têm sido demandados na fabricação de vagões ferroviários, justamente

Recebido em 19/06/2012. Texto final em 05/04/2013. devido ao seu bom desempenho mecânico e características de resistência à corrosão [3]. Diversos setores do mercado têm utilizado tal liga, dentre eles citam-se a indústria ferroviária quanto rodoviária, a indústria de petróleo e gás, indústria química, movimentação de cargas, sistema de água e de saneamento, setor elétrico e de telecomunicação [4].

Na Figura 1 é visualizado o diagrama pseudobinário do FeCr. Para teores de cromo entre 11 e $13 \%$ ocorre no resfriamento a transformação parcial da ferrita delta $(\delta)$ em austenita $(\gamma)$, permanecendo um campo bifásico $(\delta+\gamma)$ entre as temperaturas de aproximadamente $850 \mathrm{e} 1200^{\circ} \mathrm{C}$. Essas considerações somente são válidas para as ligas binárias $\mathrm{Fe}-\mathrm{Cr}$. A presença de elementos gamagênicos expande o campo austenítico para maiores teores de cromo. Para essa faixa de cromo, em condições normais de soldagem, a formação da austenita na região da ZAC (Zona Afetada pelo Calor) possibilitaria a retenção do crescimento de grão ferrítico, ou seja, essa austenita atuaria como barreira ao crescimento de grão ferrítico em altas temperaturas, podendo 
Tabela 1. Composição química do aço em estudo e metal de adição (dados do fabricante)

\begin{tabular}{cccccccccc}
\hline \multirow{2}{*}{ Processo } & \multicolumn{10}{c}{ Composição (\%) } \\
\cline { 2 - 10 } & $\mathrm{C}$ & $\mathrm{Co}$ & $\mathrm{Cr}$ & $\mathrm{Mn}$ & $\mathrm{N}$ & $\mathrm{Ni}$ & $\mathrm{O}$ & $\mathrm{Si}$ \\
\hline Box & 0,014 & 0,012 & 10,91 & 0,60 & 0,013 & 0,38 & 0,003 & 0,47 \\
Contínuo & 0,013 & 0,015 & 11,00 & 0,62 & 0,014 & 0,37 & 0,002 & 0,45 \\
EC 409 & 0,045 & - & 8,95 & 0,063 & - & 1,83 & - & 0,40 \\
\hline
\end{tabular}

Tabela 2. Parâmetros de soldagem para a realização dos testes ( $\mathrm{DBCP}=16 \mathrm{~mm})$.

\begin{tabular}{c|c|c|c|c}
\hline Consumível & Corrente (A) & Tensão (V) & Vs (cm/min) & Energia (kJ/mm) \\
\hline AWS EC 409 & 240 & 26 & 17 & 2,2 \\
\hline
\end{tabular}

com isso, obter uma melhor resistência a tenacidade ao impacto dessa região. Entretanto, a ZAC sofre um resfriamento rápido e devido à alta temperabilidade da austenita, esta poderá transformar em martensita, provocando com isso, a fragilização dessa região [5].

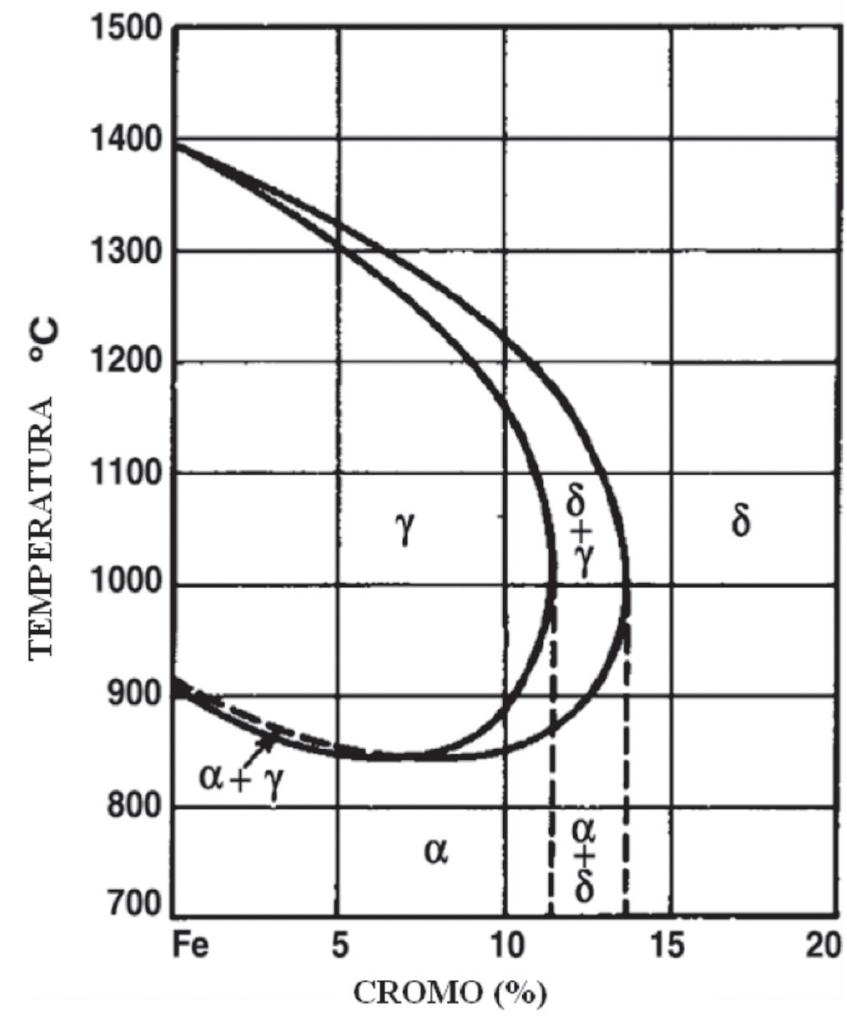

Figura 1. Diagrama de fases pseudobinário $\mathrm{Fe}-\mathrm{Cr}$, onde: $(\delta)$ ferrita delta; $(\alpha)$ - ferrita alfa; $(\gamma)$ - austenita.

As propriedades mecânicas e resistência à corrosão da região soldada dessas ligas têm sido tema de diversos estudos nos últimos anos [1, 6-8]. Baseado em tais estudos, ligas com teores de cromo na faixa de $12 \%$ e baixos teores de carbono levam a região da ZAC a ter grãos grosseiros de ferrita delta e a presença de martensita, diminuindo a resistência mecânica, a resistência a corrosão, bem como a tenacidade ao impacto dessa região. Assim, os objetivos deste estudo estão focados na avaliação microestrutural e na tenacidade ao impacto da ZAC e do metal de base do aço inoxidável ferrítico com $11 \% \mathrm{Cr}$, observando sua característica com a variação do processo de fabricação desta liga (condições de tratamento térmico após a laminação).

\section{Procedimentos Experimentais}

A Tabela 1 apresenta a composição química do aço em estudo e metal de adição (EC 409), o que difere no material de estudo é a condição de tratamento térmico após a laminação a frio. Estabeleceu-se um material em tratamento térmico em forno tipo BOX e outro em forno contínuo. No caso do processo em forno Box o material é toda inserida no forno que passa a sofrer ciclos específicos de aquecimento e resfriamento controlados. No processo a forno contínuo o material é submetido a um forno com esteira, também com temperatura controlada. Em ambos os processos o ciclo térmico é considerado pela empresa fabricante um segredo do processo de fabricação. A empresa fabricante deste material buscou obter com esses dois tipos de tratamento uma estrutura homogenia em termos de tamanho de grão com um menor custo de fabricação, caso do forno contínuo. Na Tabela 2 são apresentados os parâmetros de soldagem do processo Arame Tubular de diâmetro $1,2 \mathrm{~mm}$, arame experimental da classe AWS EC 409, sendo este um arame tubular tipo "metal cored" ferrítico.

A Figura 2 retrata a configuração da junta utilizada para a confecção dos corpos de prova do ensaio Charpy- $\mathrm{V}$ reduzido. Em todos os corpos de prova manteve-se uma abertura de junta de $3 \mathrm{~mm}$. A figura em questão apresenta a configuração da junta com a inserção de um cobre junta o qual apresentou a mesma composição do material estudado.

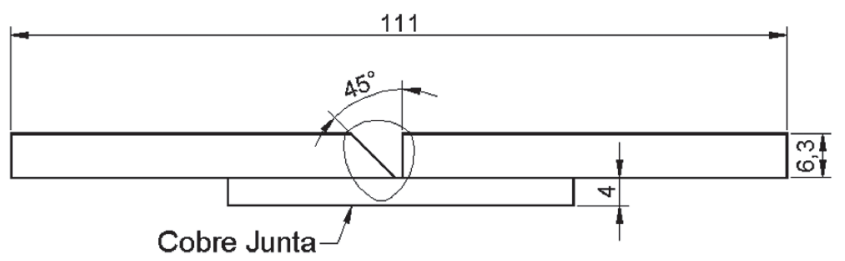

Figura 2. Configuração da junta para a retirada dos corpos de prova para o ensaio Charpy-V reduzido.

Os materiais com os dois tipos de tratamento térmico (forno tipo Box e em forno Contínuo), assim como a junta soldada, foram submetidos a uma avaliação metalográfica utilizando um 
microscópio óptico com o acoplamento de um sistema digital capaz de capturar digitalmente as imagens da ocular. Tanto o sistema digital como óptico, foram calibrados preliminarmente, utilizando padrões fornecidos pelo fabricante do equipamento. Para tanto, o material foi submetido a uma sequência de polimentos, indo até a granulação da pasta de diamante de 0,25 $\mu \mathrm{m}$ e em seguida submetido ao ataque químico, utilizando como reagente Villela's ( $1 \mathrm{~g}$ de ácido pícrico, $5 \mathrm{ml}$ de ácido clorídrico e $100 \mathrm{ml}$ de etanol). Foram realizadas medidas do tamanho de grão de acordo com a norma ASTM E 112 [9] através da técnica interceptação ou de Heyn.

Após a soldagem e retirada dos corpos de prova charpy, entalhe na região grosseira da $\mathrm{ZAC}$, os mesmos foram submetidos à análise da região soldada através do levantamento do perfil de microdureza, onde se utilizou uma carga de $200 \mathrm{~g}$ para a impressão e uma distância de $0,25 \mathrm{~mm}$ entre cada impressão. Para a realização do ensaio Charpy utilizou-se um sistema de monitoramento de temperatura avaliando a temperatura do banho $\left(25,0,-10,-20,-30,-40\right.$ e $\left.-50^{\circ} \mathrm{C}\right)$. Foram preparados banhos, mistura de etanol e nitrogênio líquido, buscando a temperatura adequada (temperatura especificada). $\mathrm{O}$ equipamento do ensaio charpy foi anteriormente calibrado segundo a norma ASTM E23. O posicionamento dos corpos de prova e outros detalhes do ensaio também seguiram a mesma norma. O fundo do entalhe para os ensaios da ZAC ficou a 1,0 $\mathrm{mm}$ da linha de fusão, conforme ilustrada na Figura 3. Foram realizados sete ensaios para cada temperatura e obtida a média e o desvio padrão.

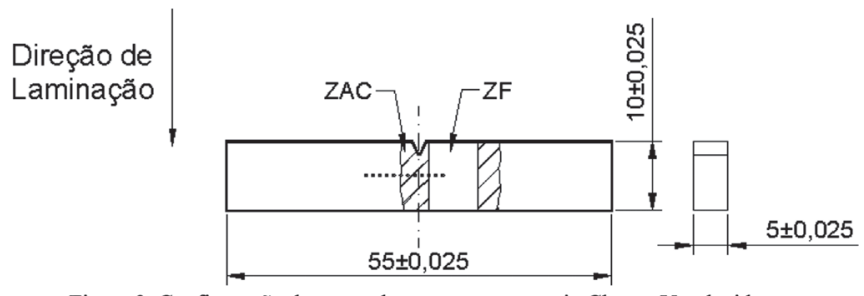

Figura 3. Configuração do corpo de prova para o ensaio Charpy V reduzido.

Figura 3. Configuração do corpo de prova para o ensaio Charpy $\mathrm{V}$ reduzido.

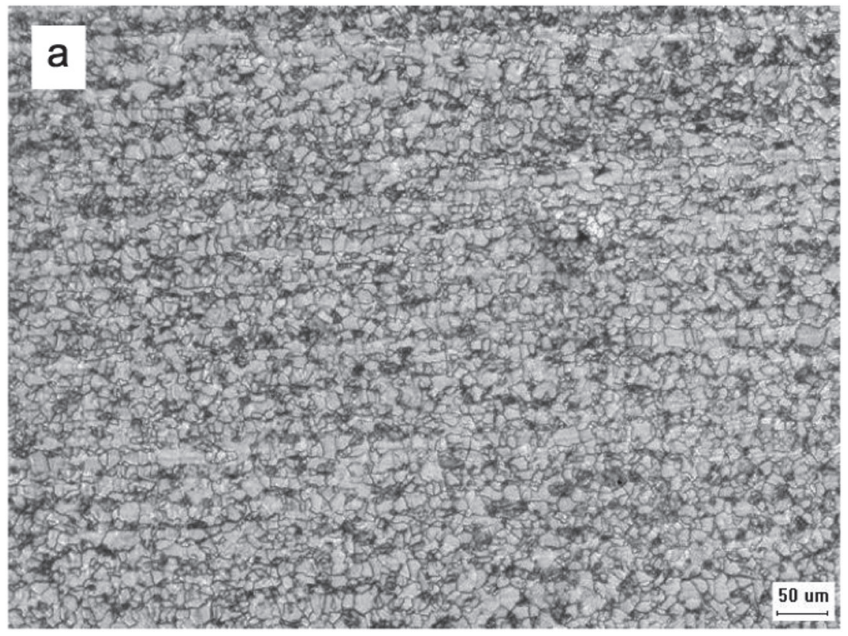

\section{Resultados e Discussão}

\subsection{Características Metalúrgicas do Metal de Base}

A Figura 4 apresenta a microestrutura ferrítica do material tratado em forno BOX, depois do procedimento de lixamento, polimento e ataque químico à base de ácido pícrico (Vilella's). Visualizam-se duas direções distintas: a de laminação (Figura 4a) e perpendicular a esta (Figura 4b). O material apresentou um tamanho médio de grão na ordem de $6 \mu \mathrm{m}$ nos dois sentidos de laminação. Esse diâmetro médio resulta em um tamanho de grão na ordem do tamanho ASTM 12, o qual se mostra uma estrutura bastante refinada.

A Figura 5 apresenta a microestrutura ferrítica para o material tratado em forno contínuo. A microestrutura se mostra mais direcionada, apresentando um formato de alinhamento de grãos de laminação. Esse material apontou um tamanho médio de grão na ordem de $10 \mu \mathrm{m}$, nos dois sentidos de laminação, cujo diâmetro médio estaria posicionado dentro do tamanho ASTM 10.

Os materiais foram submetidos ao ensaio charpy- $\mathrm{V}$ de seção reduzida, tanto o metal tratado em forno tipo Box como contínuo. Na Tabela 3 são apresentados os resultados do ensaio de tenacidade ao impacto para os dois materiais. Os valores mostrados são dados em Joule. Analisando os dados da Tabela 3 , verifica-se que a energia absorvida do ensaio charpy (em valores médios) do material tratado em forno Box apresenta-se superior ao material tratado em forno contínuo.

O material tratado em forno tipo Box apresenta um tamanho de grão menor que o tratado em forno contínuo. Segundo a literatura $[10,11]$, isso promove uma maior tenacidade ao impacto do material, isto é, maior energia absorvida no ensaio charpy. É notado que o processo de tratamento foi marcante no que diz respeito à energia absorvida. Embora se observe uma dispersão elevada para os ensaios, qualitativamente é possível salientar que o processo em forno tipo Box proporciona uma melhor característica de tenacidade ao impacto para essa liga, conforme mostrado na Figura 6. São notados nesta figura dois patamares de energia absorvida. Para o material tratado em forno tipo Box ocorre um

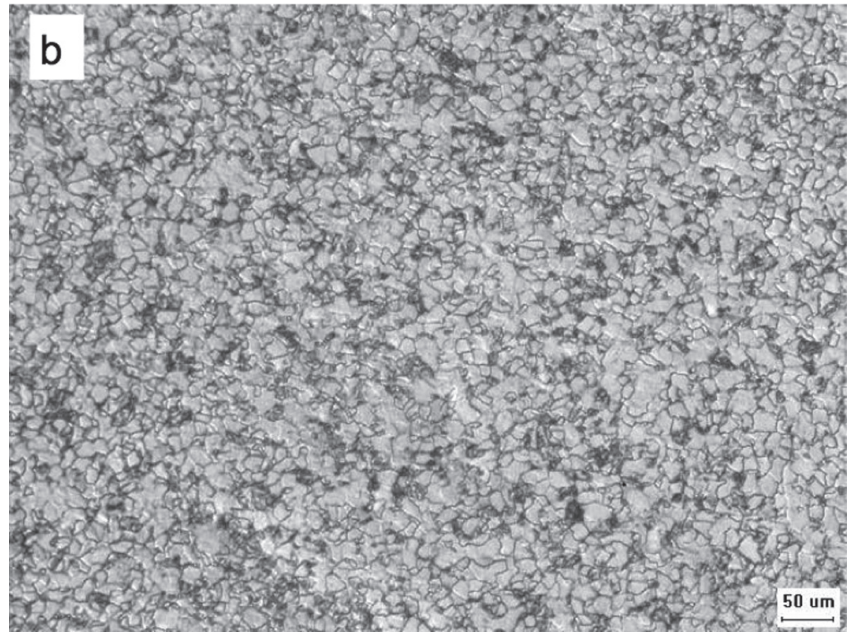

Figura 4. Microestrutura do material tratado em forno tipo Box, como recebido (ataque de Villela's). (a) sentido longitudinal à laminação; (b) sentido transversal à laminação. 

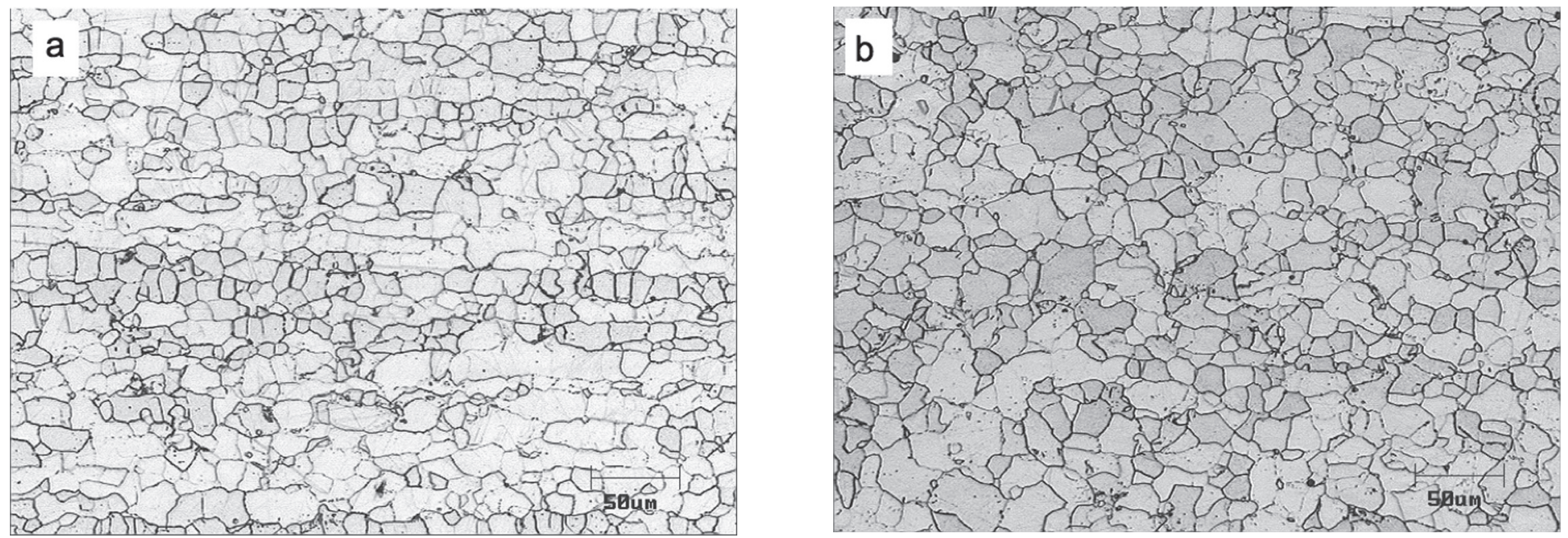

Figura 5. Microestrutura do material tratado em forno tipo contínuo, como recebido (ataque de Villela's). (a) sentido longitudinal à laminação; (b) sentido transversal à laminação.

Tabela 3. Resultado da avaliação do ensaio charpy para o metal de base.

\begin{tabular}{|c|c|c|c|c|c|c|c|c|}
\hline \multirow{2}{*}{ Tratamento } & \multirow{2}{*}{ Temperatura $\left({ }^{\circ} \mathrm{C}\right)$} & \multicolumn{5}{|c|}{ Ensaios realizados - Energia $(\mathrm{J})$} & \multirow{2}{*}{ Média (J) } & \multirow{2}{*}{ Desvio Padrão (J) } \\
\hline & & 1 & 2 & 3 & 4 & 5 & & \\
\hline \multirow{6}{*}{ Box } & -50 & 55 & 46 & 65 & 54 & - & 55 & 7,8 \\
\hline & -40 & 54 & 49 & 57 & 53 & - & 53 & 3,3 \\
\hline & -20 & 65 & 94 & 68 & 56 & - & 71 & 16,3 \\
\hline & -10 & 91 & 71 & 67 & 108 & 70 & 81 & 17,6 \\
\hline & 0 & 87 & 83 & 83 & 65 & 93 & 82 & 10,4 \\
\hline & T. Ambiente (25) & 104 & 99 & 101 & - & - & 101 & 2,5 \\
\hline \multirow{6}{*}{ Contínuo } & -40 & 7 & 5 & 15 & 51 & - & 20 & 21,4 \\
\hline & -30 & 37 & 4 & 54 & - & - & 32 & 25,4 \\
\hline & -20 & 55 & 45 & 47 & 44 & - & 48 & 5,0 \\
\hline & -10 & 64 & 49 & 40 & 56 & - & 52 & 10,2 \\
\hline & 0 & 57 & 54 & 44 & 46 & - & 50 & 6,2 \\
\hline & T. Ambiente (25) & 54 & 57 & 67 & 70 & 69 & 63 & 7,4 \\
\hline
\end{tabular}

decréscimo da energia absorvida ao impacto com a minimização da temperatura, no entanto, tais patamares de decrescimento ainda estão acima dos limites estabelecidos comercialmente para a classe desses aços, a qual apresenta uma energia de absorção ao impacto de $40 \mathrm{~J}$ à temperatura $-20{ }^{\circ} \mathrm{C}[12]$. Para o material tratado em forno contínuo é nítido o patamar inferior dos valores de energia absorvida durante o teste de impacto, comparandose com os valores atingidos pelo material tratado em forno tipo Box. Somente a partir de $-30{ }^{\circ} \mathrm{C}$ é notado que o valor de energia absorvida ao impacto já atinge valores abaixo de $40 \mathrm{~J}$.

Outra observação a ser frisada é a homogeneidade dos resultados, principalmente nas condições de menor temperatura, onde se observa um maior desvio padrão nos resultados de energia absorvida para o material tratado em forno contínuo que no forno tipo Box. Isso vem a consolidar a análise anterior, na qual se baseava na homogeneidade da microestrutura, aqui representada pela variação do tamanho de grão no material. A princípio, quanto mais homogêneo o material em relação a sua microestrutura menor será o desvio padrão das propriedades mecânicas.

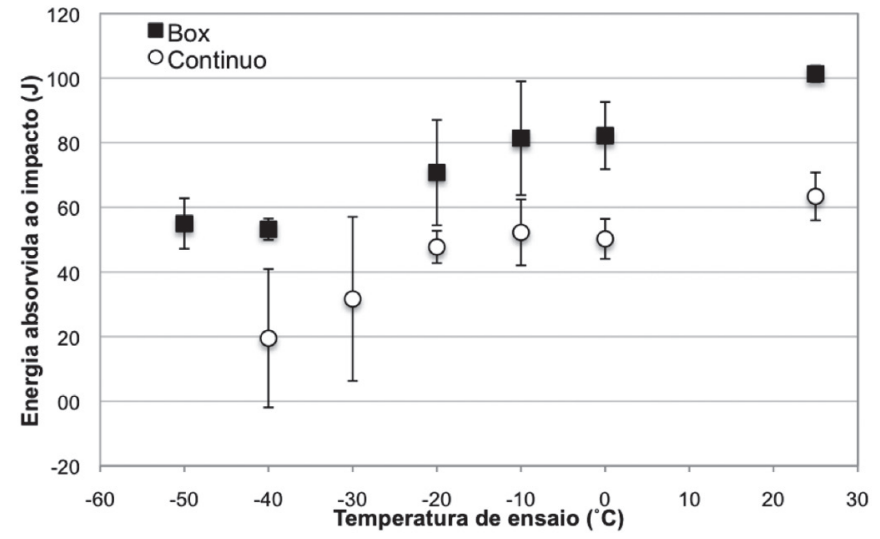

Figura 6. Resultados dos ensaios Charpy-V para o metal de base, nos dois tratamentos.

\subsection{Análise da Zona Afetada Pelo Calor (ZAC)}

Os materiais (tratados em forno tipo BOX e contínuo) foram soldados conforme condições apresentada na Tabela 2 e Figura 


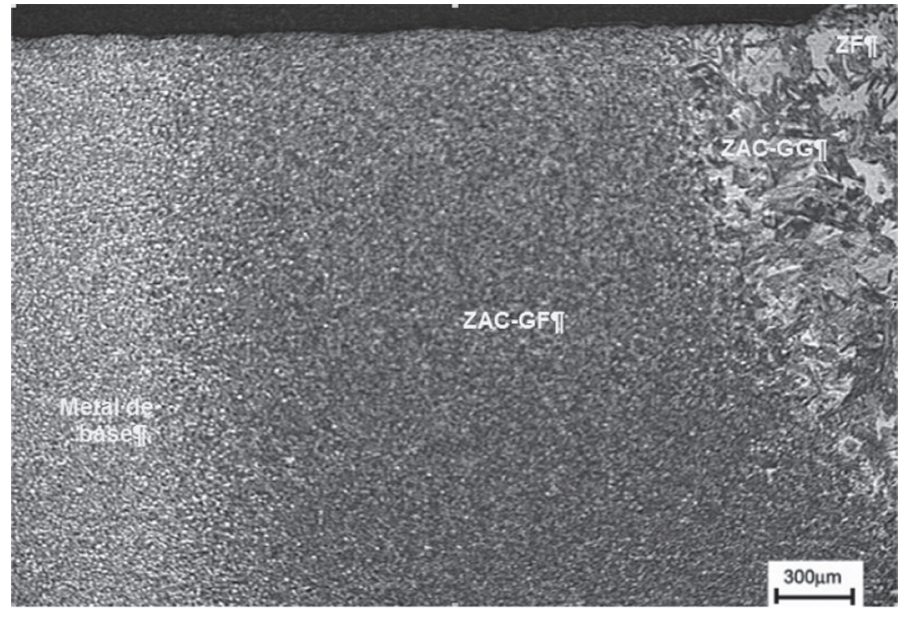

(a)

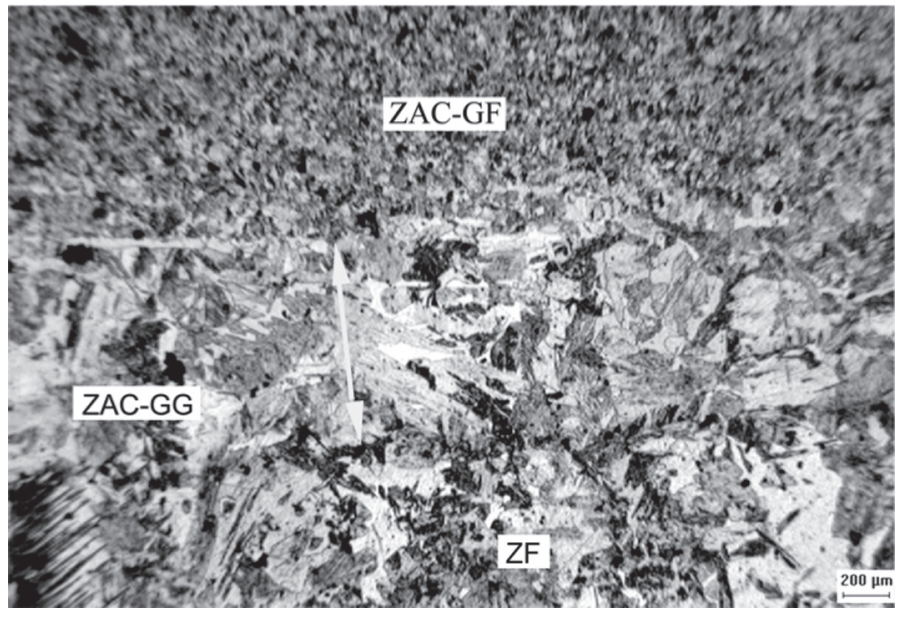

(b)

Figura 7. Solda realizada com metal tratado em forno tipo Box (Ataque Vilella's), sendo: (a) vista geral da lateral do cordão de solda; (b) vista da ZAC de grão refinados (ZAC-GF) e grosseiros (ZAC-GG).

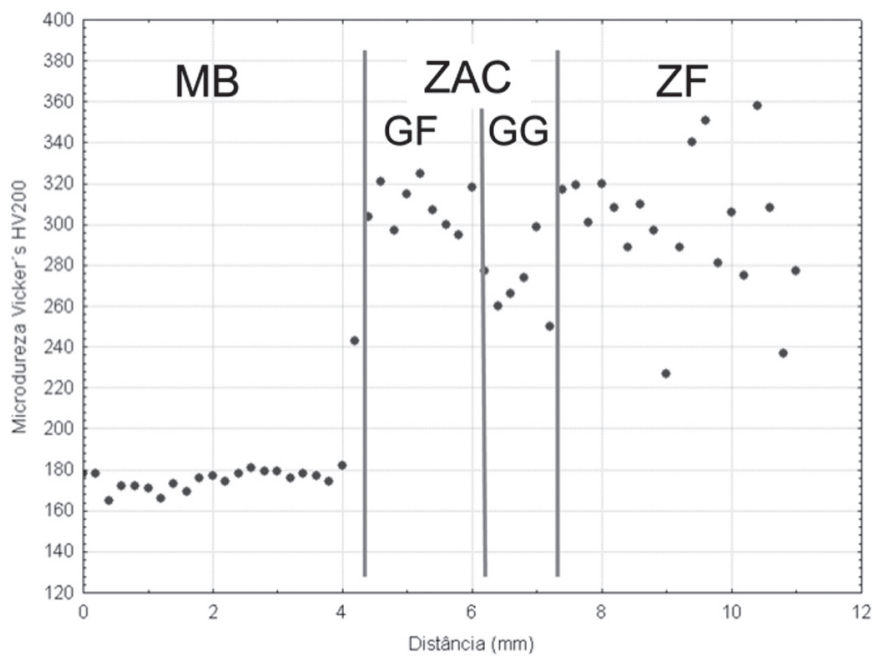

(a)

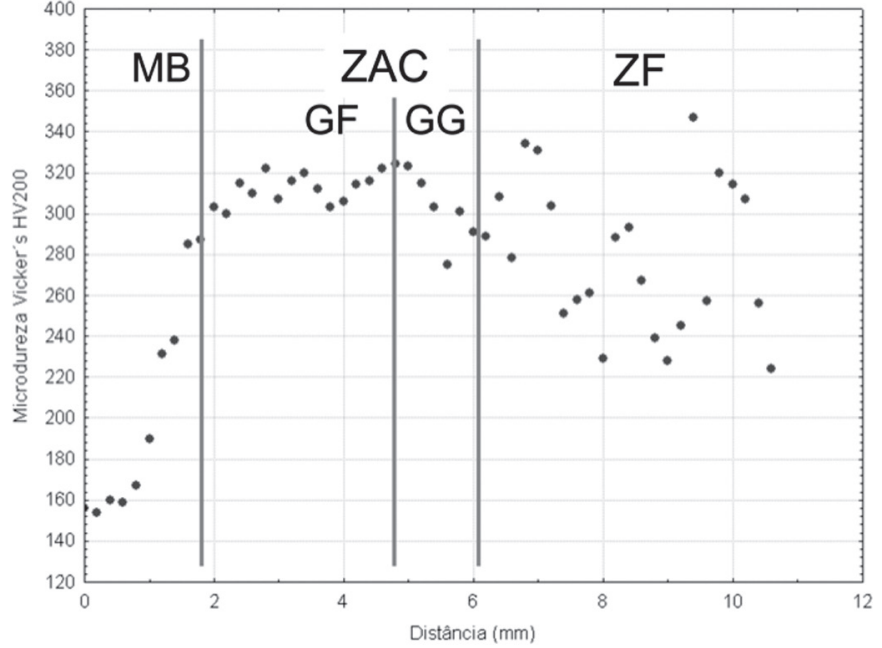

(b)

Figura 8. Perfil de microdureza realizado na soldagem com arame comercial AWS EC 409. (a) material tratado em forno tipo Box; (b) material tratado em forno contínuo.

2. A ZAC gerada nos dois materiais apresentou duas regiões, uma mais grosseira, chamada de ZAC de Grãos Grosseiros (ZAC-GG) e outra de estrutura mais refinada, ZAC de Grãos Finos (ZAC-GF). A Figura 7 apresenta as regiões para o material tratado em forno tipo Box, que se confundem em relação ao delineamento, sendo ZF a Zona Fundida do cordão de solda. Fato idêntico foi também verificado para o material tratado em forno contínuo.

A Figura 8 apresenta os perfis de microdureza medidos na extensão da junta soldada. São mostradas (valores aproximados) das distintas regiões da solda (MB, ZAC-GF, ZAC-GG e ZF) para as condições realizadas. Observa-se uma grande dispersão dos resultados de microdureza na ZF. Embora parte da ZAC (ZAC-GG) apresente uma característica similar à ZF, gerada com o consumível tubular (AWS EC 409), esta ainda mantém certa homogeneidade da microdureza, uma vez que devido aos processos de nucleação e crescimento de fase acontecer no estado sólido, o tempo de desenvolvimento dos mesmos fica limitado pelos tempos experimentados na soldagem. Essas medidas de microdureza e determinação das regiões da ZAC possibilitaram a definição da posição da ponta do entalhe do ensaio charpy na ZAC. Como mencionado na metodologia, o entalhe do corpo de prova foi posicionado a $1 \mathrm{~mm}$ da zona fundida (Figura 3). Possivelmente esses entalhes foram posicionados na ZAC-GF ou na interface das duas zonas da ZAC (GF e GG).

A Figura 9 pormenoriza a estrutura na ZAC-GG mostrando a incidência de ferrita e martensita. A microestrutura apresentada assemelha-se à observada por Carrouge et al. [13], estruturas martensíticas com incidência de ferrita delta. Segundo outras literaturas $[14,15]$ a ferrita delta seria resultado da solidificação do material fundido durante o processo de fabricação ou pontos de alta temperatura, como o que acontece na soldagem, principalmente em regiões próximas à zona de fusão. A formação de ferrita delta (conforme visto no diagrama da Figura 
1) depende do histórico térmico sofrido pelo material, além de sua composição química. Segundo o diagrama de equilíbrio para o material em estudo, o campo de ferrita delta estaria em temperaturas superiores a $1200^{\circ} \mathrm{C}$, temperatura esta atingida em alguns pontos da ZAC, principalmente na região da ZAC-GG. Esta estrutura também foi observada no material tratado em forno contínuo.

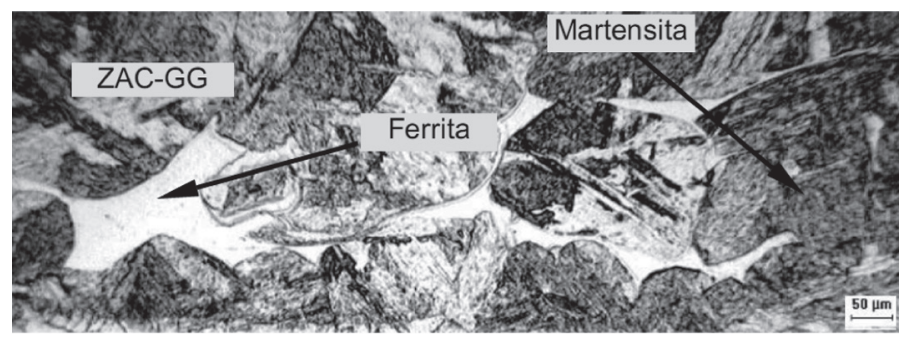

Figura 9. Região da ZAC-GG do material tratado em forno Box, salientando a presença de ferrita e da martensita (Ataque Vilella's).

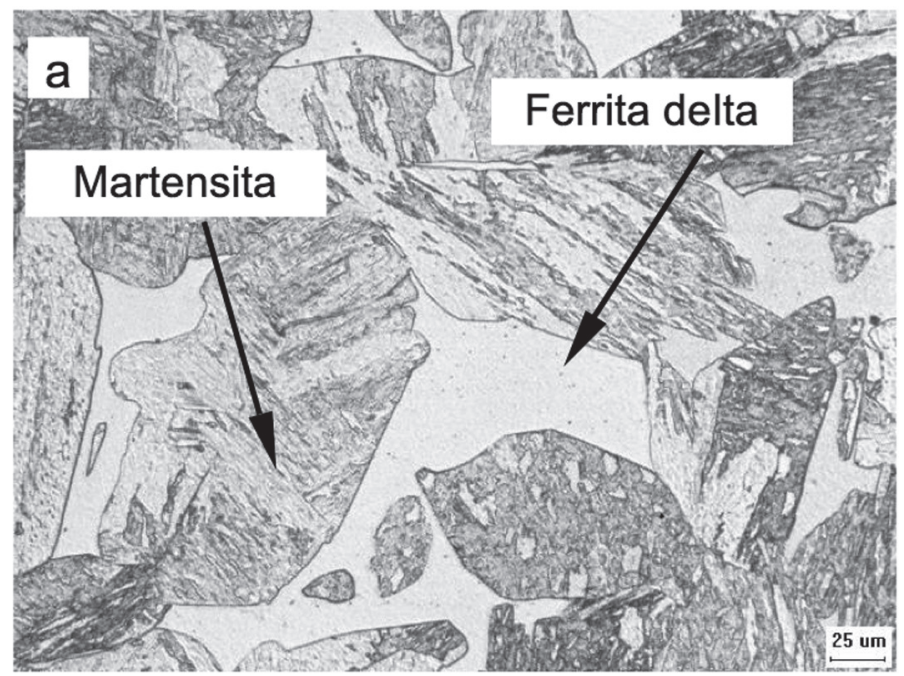

A Figura 10 mostra a microestrutura da ZAC-GG do material tratado em forno do tipo Box e a Figura 11 mostra a região da ZAC-GF do mesmo material. A Figura 12 mostra a interface entre a ZAC-GF e ZAC-GG do material tratado em forno contínuo. Verifica-se que, independente do tipo de tratamento térmico a microestrutura das duas regiões da ZAC permanece praticamente com a mesma morfologia. A ferrita delta se distribui em toda a região da ZAC, nota-se que essa estrutura tende a se modificar quanto maior a temperatura a que é submetida na região da ZAC. Na interface entre a ZAC-GF e ZAC-GG da Figura 12 é possível observar as fases de ferrita delta alinhada, e entrando na ZAC-GG observa-se a formação de ferrita delta não mais alinhada (poligonal), como se acontecesse o crescimento com o tempo de permanência em temperaturas mais elevadas da região da ZAC. Este fato foi também observado no material tratado em forno tipo BOX (Figuras 10 e 11), apesar do maior controle da microestrutura, apresenta também ferrita delta alinhada na ZAC-GF. Oñoro [15] atribui-se a formação da ferrita delta alinhada, não só à composição química, mas também ao tipo de

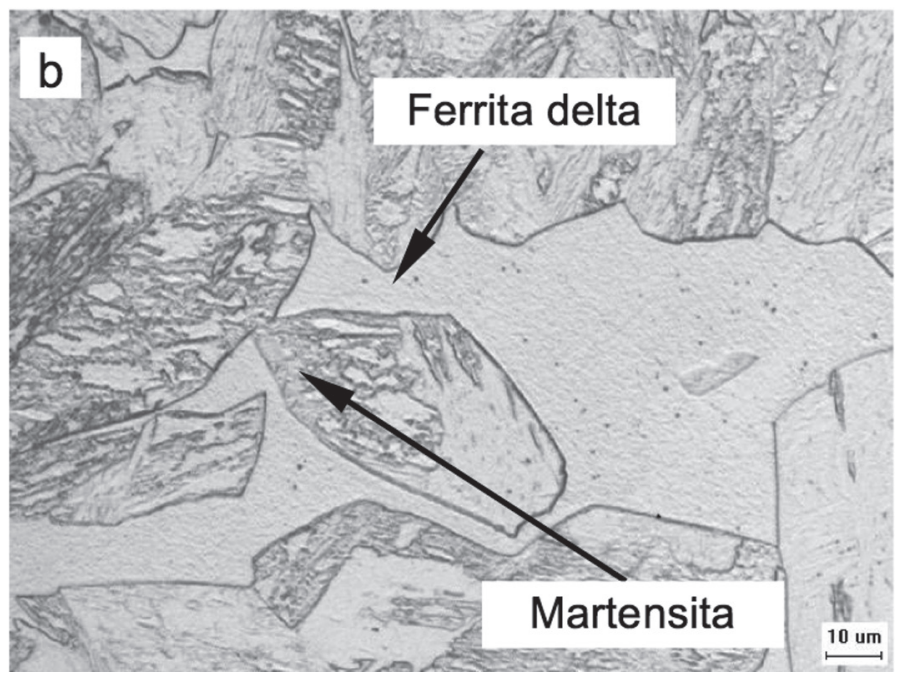

Figura 10. Ferrita delta presente na região da ZAC-GG do material tratado em forno do tipo Box.
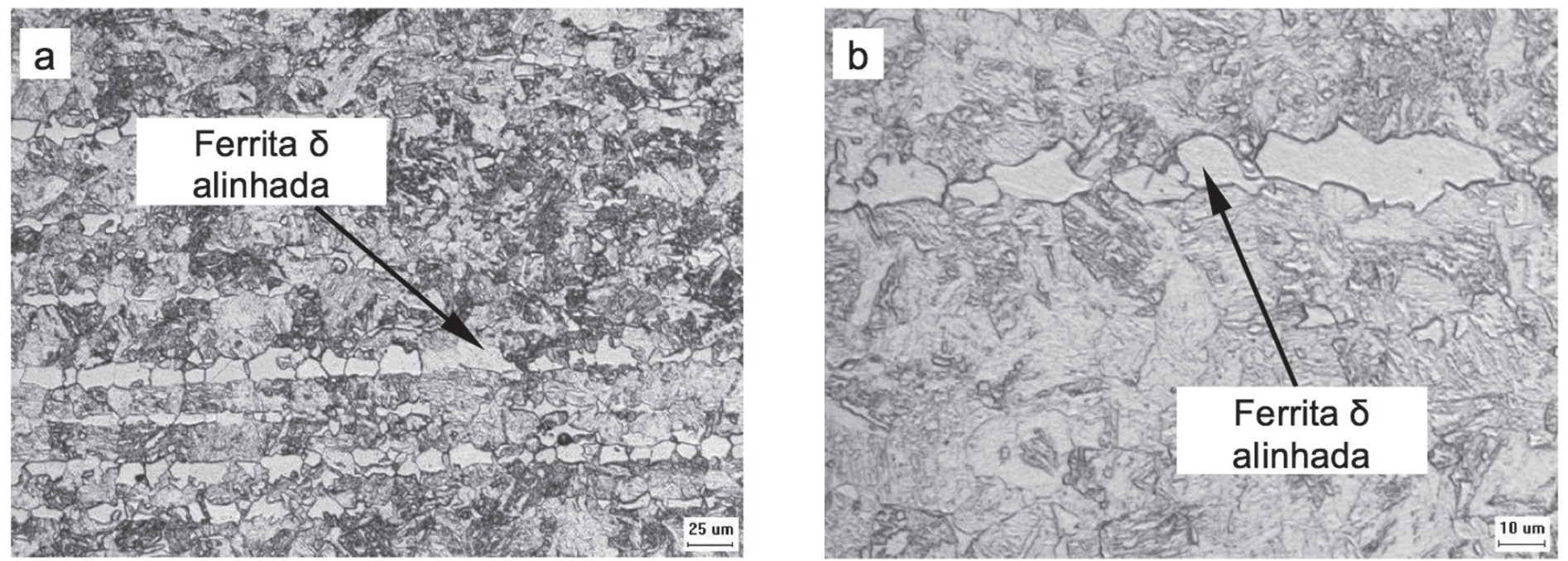

Figura 11. Ferrita delta presente na região da ZAC-GF do material tratado em forno do tipo Box. 
tratamento a que o material foi submetido antes da soldagem.

Em ambos os materiais em estudo (tratado em forno Box e em forno Contínuo), o intuito do tratamento foi o de melhorar as propriedades do material, eliminando os resquícios da conformação, homogeneizando a microestrutura, promovendo assim propriedades mecânicas adequadas. Entretanto, em ambos os tratamentos acontecem pontos de resquícios de microestruturas direcionadas (ferrita delta alinhada), que foi denominado de "bamboo shape" por Cardoso et al. [16].

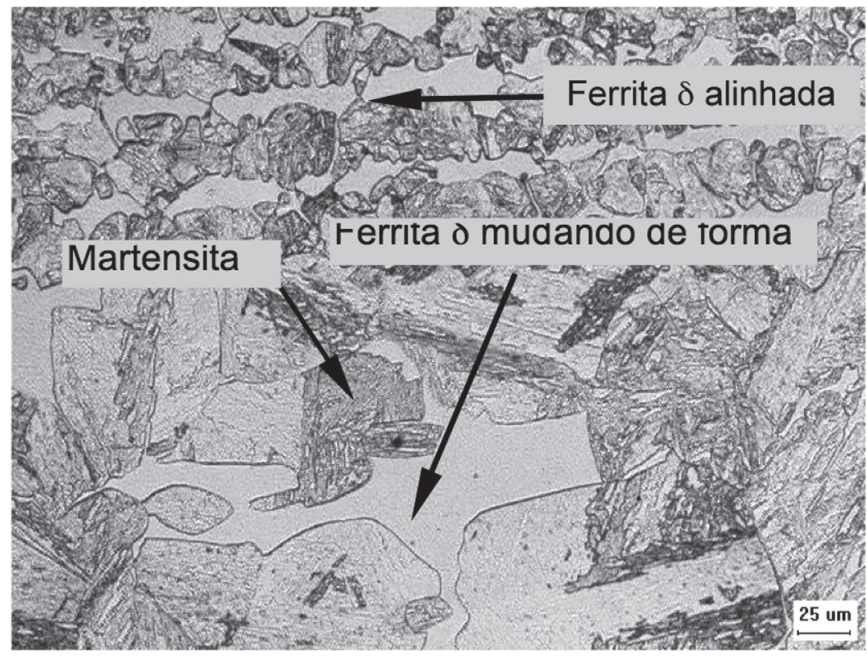

Figura 12. Interface entre a ZAC-GF e ZAC-GG do material tratado em forno contínuo.

Diversos pesquisadores $[3,13,15,16]$ frisaram o aparecimento da fase ferrita delta nas duas formas, mostradas através das Figuras 11 e 12. Essa fronteira estaria relacionada ao nível de energia de cada região, bem como das características térmicas que liga sofre. Na Figura 12 existem duas regiões bem definidas, uma com a incidência de ferrita em forma alinhada e outra com ferrita em forma poligonal. Com o aumento da energia ocorre a geração de sítios de crescimento, conforme cita Rios e Padilha [17], que através de difusão, as partículas menores são agregadas às maiores. Assim, devido ao maior nível de energia da região próxima a zona fundida (ZAC-GG), a ferrita delta pre-

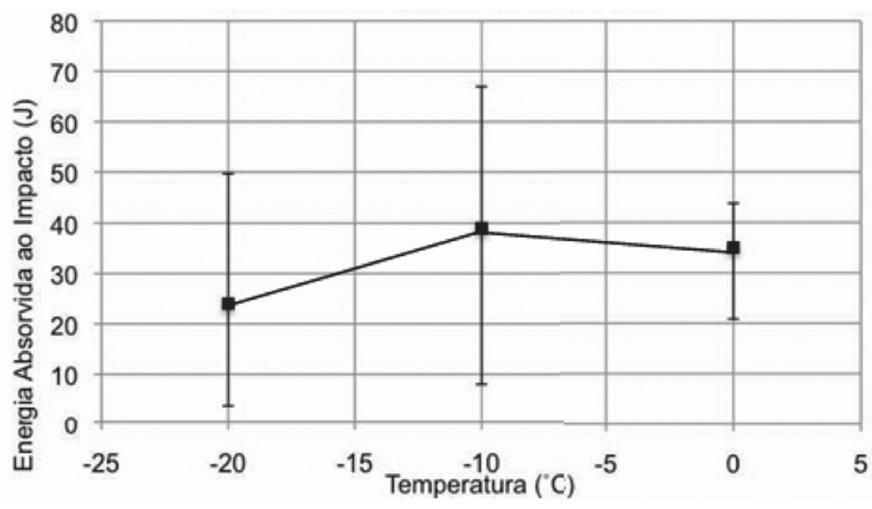

(a) sente tende a crescer e gerar a forma poligonal. É bem possível que essa formação possa acontecer ainda durante o tratamento de recozimento, independente do tipo de forno utilizado, havendo uma ativação da ferrita delta em função da energia de deformação acumulada, energia para a recristalização e por fim, a inserção da energia de soldagem.

A literatura afirma que a forma alongada de ferrita possa denegrir as propriedades mecânicas do material [13, 15]. Dessa forma, há probabilidade de que haja interferência dessa microestrutura nas propriedades do material, principalmente quando submetido a soldagem.

Foram realizados os ensaios charpy na região da ZAC com o entalhe fixado na região de transição ZAC-GG e ZAC-GF (1mm da ZF). Os ensaios foram realizados com temperaturas de $0,-10$ e $-20^{\circ} \mathrm{C}$. Foram realizados 7 ensaios para cada temperatura e obtida a média e o desvio padrão. A Tabela 4 mostra os valores de energia média $(\mathrm{J})$ e do desvio padrão $(\mathrm{J})$ obtidos do ensaio Charpy-V reduzido.

Tabela 4. Resultados do teste de charpy-V na região da ZAC dos dois materiais tratados.

\begin{tabular}{c|c|c|c}
\hline \multirow{2}{*}{ Tratamento } & Temperatura $\left({ }^{\circ} \mathrm{C}\right)$ & $\begin{array}{c}\text { Energia } \\
\text { Média }(\mathrm{J})\end{array}$ & $\begin{array}{c}\text { Desvio } \\
\text { Padrão }(\mathrm{J})\end{array}$ \\
\hline \multirow{2}{*}{$\begin{array}{c}\text { Forno Tipo } \\
\text { Box }\end{array}$} & 0 & 35,20 & 11,65 \\
\cline { 2 - 4 } & -10 & 39,00 & 21,99 \\
\hline \multirow{2}{*}{$\begin{array}{c}\text { Forno } \\
\text { Contínuo }\end{array}$} & -20 & 24,30 & 16,90 \\
\cline { 2 - 4 } & 0 & 49,20 & 42,20 \\
\cline { 2 - 4 } & -10 & 8,50 & 3,11 \\
\hline
\end{tabular}

É observada na Tabela 4 uma grande dispersão dos níveis de energia absorvida ao impacto. Os desvios padrões indicam os altos níveis de variação dos resultados nesses ensaios. Na Figura 13 são retratados os resultados da Tabela 4. Tal fato poderia ser relacionado ao entalhe, acabamento na região do entalhe ou mesmo das fases presentes. Muito embora se tenha observado o fator dimensional, bem como o posicionamento do entalhe dentro da região da ZAC, mesmo assim, a dispersão se manteve elevada.

Segundo alguns pesquisadores [18-20], diversos são os

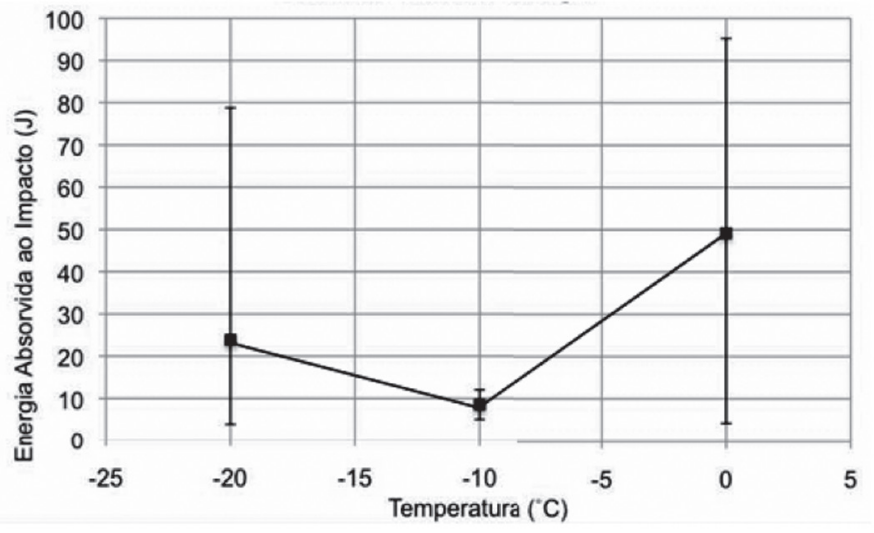

(b)

Figura 13. Resultado do teste de charpy-V na região da ZAC: (a) - Material tratado em forno tipo Box; (b) Material Tratado em forno contínuo 
fatores que interferem nas características do metal submetido a ciclos térmicos. Aqui é possível citar pelo menos três fatores que podem influenciar diretamente as características de tenacidade ao impacto para a região da ZAC do material em estudo. Assim terse-ia a variação da microestrutura, como no caso o crescimento de grão e geração de componentes como a martensita. Outro seria a precipitação de fases, possivelmente por decomposição espinodal e por fim a formação de ferrita $\delta$ em formas distintas, que embora não possuam características frágeis, aliadas ao sistema periférico (precipitados) pode promover a degradação das propriedades da liga.

Pelos resultados apresentados na Figura 13, percebe-se em termos de valores médios que o material tratado em forno tipo Box foi mais constante. Entretanto, devido à alta dispersão dos resultados, não é possível obter um resultado conclusivo, isto é, está no mesmo nível de resistência ao impacto.

Comparando os resultados do ensaio Charpy- $\mathrm{V}$ da região da ZAC (Figura 13) com o metal tratado (sem a soldagem) apresentado na Figura 6, verifica-se uma acentuada perda de resistência ao impacto na região da ZAC.

\section{Conclusões}

Em relação a caracterização dos metais de base, chegou-se às seguintes conclusões:

- A granulação observada no aço tratado em forno tipo Box se mostrou menor e mais homogênea que o aço tratado em forno Contínuo;

- A tenacidade ao impacto para o material tratado em forno tipo Box foi superior ao material tratado em forno Contínuo.

Com relação à caracterização da ZAC é possível obter as seguintes conclusões:

- O material em estudo, independente do tratamento térmico pós laminação, apresentou duas regiões na ZAC, uma de granulação refinada e outra de granulação grosseira com a presença de ferrita delta;

- Na região de granulação grosseira a ferrita delta apresentou um formato poligonal e na região de granulação refinada apresentou um formato mais alongado;

- A tenacidade ao impacto (energia absorvida) apresentou uma grande dispersão, provavelmente influenciada pela presença tanto de precipitados como de ferrita delta;

- O tipo de tratamento aplicado no material não apresentou influência marcante no nível de tenacidade ao impacto da ZAC;

- Verificou-se uma perda acentuada da tenacidade ao impacto na ZAC em relação ao metal de base.

\section{Agradecimentos}

Os autores agradecem à FEMEC/UFU, ACESITA, CNPq, FAPEMIG e a CAPES pelo apoio institucional e financeiro para a realização do trabalho.

\section{Bibliografia}

[1] TABAN, E.; DELEU, E.; DHOOGE, A.; KALUC, E., Laser welding of modified $12 \% \mathrm{Cr}$ stainless steel: strength, fatigue, toughness, microstructure, and corrosion properties. Mater, v.30, n.4, 2009.

[2] COLUMBUS. NN. 3CR12 technical data. Technical data catalogue. South Africa: Columbus Stainless; June 2007.

[3] WANG L.; SONG, C.; SUN, F.; LI, L.; ZHAI Q. Microstructure and mechanical properties of $12 \mathrm{wt} . \%$ ferritic stainless steel with $\mathrm{Ti}$ and $\mathrm{Nb}$ dual stabilization. Mater, v.30, p.49-56, 2009.

[4] AK STEEL. Product data bulletin-409Ni stainless steel data. Product catalogue. America: AK Steel Corporation; 2007.

[5] ZHENG, H.; YE. X.; JIANG, L.; WANG, B.; LIU, Z.; WANG, G. Study on microstructure of low carbon $12 \%$ chromium stainless steel in high temperature heat-affected zone. Materials and Design, v.31, p.4836-4841, 2010.

[6] GREEFF, M. L.; DU TOIT, M.:Looking at the sensitization of $11-12 \%$ chromium EN 1.4003 stainless steels during welding. Weld Journal, v. 85, n.11, p. 243-251, 2006.

[7] ROIT, M. D.; VAN ROOYEN G. T.; SMITH, D. Heataffected zone sensitization and stress corrosion cracking in $12 \%$ chromium type 1. 4003 ferritic stainless steel. Corrosion, v.63, n.5, p.395-404, 2007.

[8] VAN WARMELO, M.; NOLAN, D.; NORRISH, J. Mitigation of sensitation effects in unstabilised $12 \% \mathrm{Cr}$ ferritic stainless steel welds. Mater Sci. Eng. A., p.157-169, 2007.

[9] ASTM E 112 - Standard Test Methods for Determining Average Grain Size. ASTM International, PA, United States, 1996.

[10] DIETER, G. E. Metalurgia Mecânica. 2a Ed. Guanabara, Rio de Janeiro, 1981.

[11] BERBENNI, S.; FAVIER, V.; BERVEILLER, M. Impact of the grain size distribution on the yield stress of heterogeneous materials. International Journal of Plasticity, v.23, p.114-124, 2007

[12] AK STEEL. Product data sheet-41003 stainless steel data. Product catalogue. America: AK Steel Corporation; 2007.

[13] CARROUGE, D.; BHADESHIA, H. K. D. H.; WOOLLIN, P. W. Effect of d-ferrite on impact properties of supermartensitics stainless steek heat affected zones. Science and Technology of Welding and Joining. v. 9, n. 5, 2004.

[14] PUJAR, M.G.; DAYAL, R. K.; GILL, P. S.; MALHOTRA, S. N. Microstructural evaluation of molybdenum containing stainless steel weld metals by a potentiostatic etching technique. Journal of Materials Science, v.33, p. 2691-2700, 1998.

[15] OÑORO, J. Martensite microstructure of $9-12 \% \mathrm{Cr}$ steels weld metals. Journal of materials Processing Technology, v.180, p.137-142, 2006.

[16] CARDOSO, P. H. S.; KWIETNIEWSKI, C.; PORTO, B, J. P.; REGULY, A.; STROHAECKERA, T. R.: The influence of delta ferrite in the AISI 416 stainless steel hot workability. Materials Science and Engineering A, v. 351, Issues 1-2, 25, 2003.

[17] RIOS, P. R.; PADILHA, A. F. Transformações de Fase. Artliber Editora LTDA, São Paulo, SP. 2007.

[18] KOU, S.: Welding Metallurgy. 2ed. New York: John Wiley \& Sons, 2003.

[19] LIPPOLD, J. C. and KOTECKI, D. J.: Welding Metallurgy and Weldability of Stainless Steels. John Wiley and Sons, 
Hoboken, New Jersey, USA. 2005.

[20] TOTEMEIER, T.C.; SIMPSON, J. A.; TIAN, H.: Effect of weld intercooling temperature on the structure and impact strength of ferritic-martensitic steels. Materials Science and Engineering A, v. 426, p.323-331, 2006. 